DOI 10.37882/2223-2982.2021.01.23

\title{
СОВЕРШЕНСТВОВАНИЕ НАВЫКОВ САМООБУЧЕНИЯ У СТУДЕНТОВ В КОНТЕКСТЕ МЕДИАОБРАЗОВАНИЯ
}

\section{IMPROVEMENT OF STUDENTS' SELF-LEARNING SKILLS IN THE CONTEXT OF MEDIAEDUCATION}

\section{Obukhova}

Summary: The increasing influence of the media environment on people's minds caused the penetration of media technologies into various spheres of human life and stimulated the growth of scientific activity in universities. As a result, the primary goal has become to train students with highly developed media educational competencies, which means that they are to be ready for life-long learning. The urgency of the problem has increased significantly during the pandemic.

Keywords: foreign language, media competence, self-learning skills, formal and non-formal education, life-long learning, media education, types of control, computer testing, control improvement.
$\mathrm{T}$ енденция развития современного общества определяет потребности человека в непрерывном и обучении в течении всей жизни, как в профессиональной сфере, так и в плане развития личности. Иными словами, быстро меняющаяся реальность с постоянно усложняющимися формами медиа-гаджетов требует постоянного совершенствования навыков информационной грамотности, которые должны быть реализованы в процессе самообразования личности. Необходимым условием успешного самообучения является наличие у студентов развитых навыков самоподготовки, то есть знаний, умений и установок, связанных с процессом самообучения. Эти компетенции должны формироваться на этапе вузовской подготовки. Они включают навыки медиа- и информационной грамотности, то есть, навыки безопасного использования средств массовой информации (медиа - иммунитета), критического мышления, анализа информации и ее использования для самовыражения, для успешной творческой работы, то есть навыки самостоятельного обучения через медиасреду.

Педагоги подразделяют образование на формальное, которое включает в себя аудиторную работу студентов, стажировку для получения практического опыта и внеаудиторную самостоятельную работу [4,с. 83], которая может быть индивидуальной и групповой. В то время, как задачей неформальной формы обучения является активное вовлечение студентов в образовательную деятельность. основанную на их опыте, реальных действиях, общении и взаимодействии. Примеры таких
Обухова Лариса Юрьевна

старший преподаватель, Финансовый университет при Правительстве Российской Федерации (г. Москва) lora.yur@mail.ru

Аннотация: Усиливающееся влияние медиасреды на сознание людей обусловило проникновение медиатехнологий в различные сферы человеческой жизни и стимулировало рост научной деятельности в вузах. В следствие чего, важнейшей задачей становится совершенствование у студентов медиаобразовательных компетенций, а значит, готовности к постоянному самообучению в течении всей жизни. Актуальность проблемы значительно возросла в период пандемии.

Ключевые слова: иностранный язык, медиакомпетентность, навыки самоподготовки, формальное и неформальное образование, обучение на протяжении всей жизни, медиаобразование, виды контроля, компьютерное тестирование, совершенствование контроля.

форм могут быть, круглые столы, конференции, конкурсы. Важность такого образования в цифровом обществе неуклонно возрастает Неформальное образование можно охарактеризовать как айсберг: в основном невидимый на поверхности и огромный в своих глубоких неформальных аспектах [9].

Формальные и неформальные виды учебной деятельности обладают взаимодополняющими свойствами, такими как: системность, универсальность охвата, способность выступать в качестве инструмента овладения базовыми компетенциями, заданной стратегией профессионального развития - составляют основу формального образования; С другой стороны, вариативность, добровольность, умение быстро решать краткосрочные задачи, адаптировать профессиональную подготовку к меняющиеся условия рынка труда - свойства неформального образования [10]. Очевидно, что интеграция этих видов деятельности создаст возможность для расширения образовательной среды вуза, позволит совершенствовать образовательные стандарты, и углубить содержание образования, так как "формальное образование может рассматривается как система государственных стандартов, а неформальное образование - как система совершенствования образовательных стандартов и приведение их в соответствие с новым уровнем знаний и практики" [2, с 37]

На основе сформированных компетенций молодежь может самостоятельно осуществлять самообучение и 
постоянно повышать свой медиаобразовательный уровень, а следовательно, развивать свою медиакомпетентность, что является основной целью обучения на протяжении всей жизни человека.

Современное медиаобразование имеет несколько подходов, одним из которых является самостоятельное обучение, реализуемое на протяжении всей жизни человека. Для того, чтобы человек его реализовал, необходимо еще в период вузовской подготовки сформировать готовность к самообучению: навыки самоподготовки и медиакомпетентности.

Следует отметить, что под самообучением мы понимаем целенаправленную, систематическую, автономную деятельность индивида по получению, усвоению и творческой переработке знаний [1, с. 54]. В процессе такой деятельности студент самостоятельно определяет цель и содержание своего обучения, а также контролирует свой уровень подготовки. Тем не менее, данный процесс также требует корректировки и контроля со стороны преподавателя. Контроль учебных знаний это сопоставление фактических результатов обучения с запланированными, и установление их соответствия нормам и стандартам [3].

Существует еще понятие самообразования. Если сравнивать самообразование и самообучение, то первое связано с общим развитием личности, а второе - с ее профессиональным ростом или освоением новой профессии, поэтому самообразование невозможно без самообучения. Таким образом, навыки, которые человек развивает в процессе самообучения, позволяют ему успешно заниматься самообразованием. Если целями самообучения являются получение, усвоение и творческая переработка знаний, то целями самообразования обычно являются самовоспитание, самопонимание, самосовершенствование, духовный рост и самореализация. Самообразование связано с поиском и усвоением накопленного человечеством социального опыта, а также с психологической, теоретической и практической готовностью личности к самообучению. [1, с. 54]. Как правило, ученые рассматривают индивидуальную готовность к самообразованию как овладение личностью всеми компонентами самообразовательной деятельности.

Для того, чтобы человек развил необходимые качества до требуемого уровня, не достаточно лишь устойчивой внутренней убежденности. Многое зависит от способностей человека, развития его воли, умения адекватно реагировать на изменяющиеся внешние факторы. Считается, что индивидуальная готовность к самообучению в контексте медиакомпетентности означает выработанные личностью навыки самообучения, а именно регулярные действия по самостоятельному получению, усвоению и творческой переработке знаний, имеющие позитивный результат [1]. Выделяют следующие группы навыков самообучения:

- коммуникативные навыки (навыки правильной работы с медийной информацией, ее быстрого поиска и преобразования);

- навыки научно-исследовательской деятельности (навыки анализа, критического творческого мышления- медиаграмотности и медиа-иммунитета).

Активному развитию этих навыков способствует организация учебного процесса в университете, которая позволяет расширить и укрепить междисциплинарные связи и активно вовлекать студентов в исследовательскую деятельность, начиная с первого курса, когда студенты привлекаются к участию в междисциплинарных проектах.

Наличие развитых навыков самоподготовки означает готовность личности к самообучению с использованием информационных технологий, то есть закладывает краеугольный камень медиакомпетентности и, таким образом, способствует непрерывному развитию этой готовности в соответствии с быстро меняющейся медийной реальностью. При этом медиакомпетентность в целом определяется как личностное качество, проявляющееся в готовности к отбору, использованию, оценке, созданию и отправке медиаматериалов различных форматов, анализу возможностей использования медиа в социальной среде [7]. Можно выделить следующие составляющие медиакомпетентности: опыт общения со СМИ и реальным миром, активное использование навыков в медиапространстве и готовность к самообразованию.

В наше время образование и самообразование представляются невозможными вне средств массовой информации и медиаматериалов. И.В. Челышева определяет цель современного медиаобразования как формирование медиакомпетентной личности, способной к творческому взаимодействию с произведениями медиакультуры, к их самостоятельному анализу и оценке, к полному использованию воспитательного и развивающего потенциалов медиасреды в различных сферах нашей жизни. Такое медиаобразование может осуществляться в процессе неформального образования личности, под которым понимается любой вид систематически организованной деятельности, которая может отличаться от деятельности учреждений, входящих в формальную образовательную систему (вузов). Между тем неформальное образование является неотъемлемой частью непрерывного личностного самосовершенствования и должно основываться на инновационных методах обучения, благодаря которым студент перестает быть пассивным получателем информации, а преподаватели становятся в значительной степени консультантами, наставниками и посредниками. Целью такого образования является создание условий для гибкого обновления зна- 
ний и умений обучающихся, а принципиальным отличием от формальной образовательной модели является принятие образования как атрибута жизни человека. [5, с. 71]. Такое образование поможет выпускнику вуза непрерывно совершенствовать индивидуальные знания в областях образовательного сегмента, подверженного быстрым изменениям в связи с постоянно ускоряющимися процессами информатизации общества и имеющего отношение к студенту в силу его будущей профессии или личностного развития.

Неформальное личностное образование способствует развитию готовности к самообучению на протяжении всей жизни, а успех во многом зависит от устойчивой мотивации личности к познанию нового и развитой силы воли. Реализация познавательных потребностей осуществляется через формирование познавательных установок личности. Познавательная установка способствует длительному стабильному состоянию личности, проявляющемуся в положительном отношении к исследовательской деятельности, в устойчивом познавательном интересе, стабильности познавательных потребностей. Наличие устойчивой мотивации и культурной воли присущи человеку, обладающему позитивной Я-концепцией, поскольку последняя тесно связана с процессами рефлексии, самоорганизации, самоконтроля, самоопределения, самореализации и самоутверждения [1]. Поэтому если человек мотивирован на готовность к самообучению, то его Я-концепция будет способствовать формированию у него устойчивой мотивации к этой деятельности, возводя ее в ранг непрерывного образовательного процесса.

Поскольку современная цивилизация, культура, общество, человек - все эти понятия неразрывно связаны с медиакультурой, то развитие индивидуальных умений самообучения нельзя рассматривать в отрыве от медиаобразовательных процессов[5]. В эпоху постоянно растущего потока медиаинформации они активно внедряются в систему образования, способствуя приобретению знаний, воспитанию, развитию методов и технологий, а это актуализирует самообразование и самообновление личности. Поэтому медиаобразование предполагает развитие индивидуальной готовности к самообучению. Это связано с современным использованием различных медиатехнологий в образовательном процессе и применением их, как в стандартных, так и в нестандартных ситуациях, с повышением степени доступности и адаптивности знаний для обучающихся.

Медиаобразование личности решает следующие задачи - научить правильно читать медиаматериалы; развить умение рационально воспринимать и оценивать информацию, развивать критическое мышление и эстетический вкус, интегрировать знания и умения, полученные в вузе [7, с.18]
По мнению Эркана Баля, социальные медиа улучшают навыки совместного обучения и помогают студентам легче общаться со своими преподавателями [8, с. 177]. Кроме того, использование медиатехнологий повышает эффективность как образовательного процесса, так и процессы управления и контроля.

Современная образовательная среда активно включает в себя компоненты медиасреды: социальные сети, блоги, Youtube-каналы и др. Обучающикся вовлекаются в социальные сети в рамках академической среды, а преподаватели также стараются ее использовать. Социальные медиа - это среда, в которой студенты чувствуют себя собственниками (в отличие от университетских онлайн-сред), что способствует улучшению коммуникации студентов. Доступность медиа-материалов и преимущества аутентичных онлайн-приложений позволяют создать богатую и разнообразную образовательную среду, комфортную для студентов. Следовательно, современная среда, полная различных средств массовой информации, имеет возрастающий потенциал для процессов самообучения. Качественная подготовка медиаобразованных кадров может помочь им уверенно и быстро ориентироваться в постоянно расширяющемся потоке информации, критически оценивать эту информацию и использовать ее по назначению. Это позволит им успешно учиться и работать в медиапространстве, отбирая ценные продукты медиакультуры и избегать негативного манипулирующего воздействия медиатекстов. Таким образом, это позволит повысить медиаграмотность самообучающегося и саморазвивающегося человека, положительно способствуя росту коммуникативных и исследовательских умений для научной деятельности и позволит избежать негативного воздействия средств массовой информации.

Ведущая идея медиаобразовательной концепции заключается в том, что в современном мире конструктивное формирование и развитие готовности личности к самообучению в процессе обучения в вузе должно осуществляться путем актуализации познавательных потребностей личности в рамках проектно-продуктивной образовательной деятельности. Это возможно за счет расширения информационно-образовательной среды вуза и востребованных для решения поставленных задач ресурсах внешней образовательной медиасреды.

Практика показывает, что студент, не имеющий навыков самоподготовки, не знает алгоритмов, соответствующих навыкам самообучения; обладает недостаточной компьютерной грамотностью, часто ошибается и имеет низкую продуктивность; не способен выполнять исследовательские и творческие задания. Учащийся со средним уровнем развития этих навыков быстро и качественно использует их в стандартных ситуациях; обладает некоторыми сформированными медиаобразовательны- 
ми компетенциями, обладает стремлением планировать и решать исследовательские и творческие задачи, однако, при выполнении таких задач в ряде случаев допускает ошибки. Наконец, обучающийся с высоким уровнем развития этих навыков, умеет гибко оперировать ими, как в обычных, так и в непредвиденных ситуациях; обладает сформированными медиаобразовательными компетенциями; способен индивидуально получать знания и творчески их обрабатывать [1с.55].

Можно предположить, что реализация образовательного процесса с учетом данного подхода позволит лучше понять, в каком направлении студентам следует работать, чтобы повысить свою профессиональную компетентность, развивая готовность к самообучению в любых ситуациях.

В условиях пандемии и режиме самоизоляции дистанционное обучение стало развиваться очень интенсивно. Но в век стремительного потока информации задача преподавателей сводится не только к тому, чтобы проводить вебинары и давать задания, необходимо ставить более далекие цели - научить студентов самостоятельной поисковой работе, оценивать, какие сайты дают достоверную информацию, а каким не следует доверять, то есть формировать медиа - иммунитет у студентов. Этой задаче служат все современные форматы обучения иностранному языку: е-, m-learning, distance learning (англ.) и другие. В высшей школе необходимо сформировать компетенции, необходимые выпускникам в дальнейшей профессиональной деятельности. Задача педагогов заключается в том, чтобы выработать у студентов потребность и привычку к самостоятельному углублению знаний, к дальнейшему самосовершенствованию. В настоящее время основной задачей вуза является подготовка выпускников нового поколения, думающих, креативных личностей, готовых к самостоятельному поиску актуальной информации, к практическому использованию полученных в вузе умений и навыков. Таким образом упор делается самостоятельную познавательную деятельность студентов, интегрированную в учебный процесс. То есть, основной целью курса «Иностранный язык» становится развитие навыков самостоятельной учебной и научно-исследовательской деятельности студентов в процессе совершенствования профессиональной иноязычной компетентности.

Так, во время самоизоляции, когда не было возможности посещать занятия очно, студентов перевели на дистанционные вебинары в программе Microsoft Teams. По мнению Чикилевой Л.С., дистанционное обучение меняет содержание самостоятельной работы студентов, повышая мотивацию, способствует интенсификации образовательного процесса [6, с.511]. Дистанционные вебинары требуют более глубокого подхода, при котором обучающиеся должны понимать поставленные задачи и уметь применять знания в новых ситуациях, а также освоения большего объема материала, изучение того, что требуется для успешной сдачи экзаменов и получения максимально высоких оценок, исходя из опыта и результатов прошлых экзаменов. В то время, как поверхностный подход, свойственный некоторым студентам, предполагает лишь воспроизведение пройденного материала и изучение только того, что требуется для получения зачета.. Основным недочетом многих из них было то, что они не пересмотрели свое отношение к занятиям своевременно.

Спустя два месяца работы в режиме онлайн (майиюнь 2020) среди студентов 1-3 курса (150 человек) финансово-экономического факультета Финуниверситета был проведен опрос. Исследование проводилось путем прямого анкетирования студентов (на английском языке) с последующей систематизацией и обобщением результатов исследования, направленных на выявление текущих тенденций и их интерпретацию, на основе полученных данных. Анкета включала вопросы для оценки способности студентов к самообучению и сформированности их навыков самоподготовки, а также рассматривался вопрос о степени адаптивности и готовности студентов работать в новом режиме.

Для успешной самоподготовки студенты нуждаются в определенных навыках и новых подходах к обучению. Признаками готовности к самостоятельному обучению можно считать: умение выполнить работу от начала до конца самому, организованность, самодисциплину, способность эффективно общаться, умение скорректировать цели

Опрос показал, что у многих студентов (44\%) уже были вполне сформированы навыки самостоятельной работы и они продолжали готовиться к занятиям также, как и раньше, не сбавляя темпа (Рис.1.)

\section{Оценка уровня сформированности навыков}

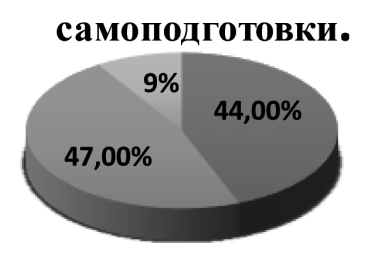

Рис. 1. Данные опроса студентов бакалавриата Финуниверситета, 2020

У другой группы студентов (47\%) было отмечено, что переход на обучение онлайн для них, изменил и объем, и содержание самостоятельной работы, повысилась мотивация, что в результате углубило как учебную, так и исследовательскую работу студентов, самые сильные из них усложнили свои цели и задачи и использовали 
освободившееся время для проведения научно - исследовательской работы: написания и публикации статей. Однако, нашлись и такие (9\%!), у которых навыки самостоятельной работы не были сформированными и которые решили, что дистанционный формат и связанное с ним снижение текущего контроля, позволяют им расслабиться и меньше уделять внимания подготовке к занятиям, что, конечно же серьезно сказалось на их итоговых результатах. Для них переход оказался довольно болезненным, им сложно было организовать свою работу: подготовку и участие в занятиях.

На следующем этапе обучающимся необходимо было провести самооценку своей текущей ситуации, учебных привычек, семейной ситуации и поддержки дома, работы гаджетов и интернет сети (Рис. 2.).

\section{Оценка степени адаптивности студентов к новому формату обучения

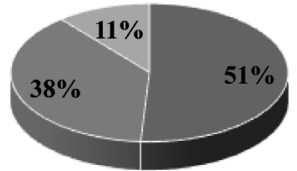 \\ - 51\% Ощущали дефицит общения \\ - 38\% Были готовы попробовать что-то новое}

Рис. 2. Данные опроса студентов бакалавриата Финуниверситета, 2020

Как мы видим, мнения студентов разделились: 51\% бакалавров - очной формы обучения отдали предпочтение аудиторным занятиям и прямому контакту с одногруппниками и преподавателем в стенах университета. Они также понимали, что переход в формат онлайн был вынужденной мерой, и посчитали, что к этому следует прибегать только в случае крайней необходимости.

Другие 38\% бакалавров увидели новые возможности и оценили преимущества дистанционного обучения (особенно, в плане свободного времени) и высказали мнение, что этим форматом нужно пользоваться шире и чаще, то есть, были настроены вполне оптимистично.

Однако, целая группа студентов (11\%) дали довольно пессимистическую оценку тотальной цифровизации учебного процесса, недовольные тем, что им пришлось приложить усилия и потратиться на видео - камеры, планшетники, модемы и прочие гаджеты, которые делают онлайн связь более качественной, так как перебои с интернет-трафиком действовали контрпродуктивно.

Оценить уровень сформированности навыков самостоятельной работы студентов при выполнении творческого задания позволяют такие критерии, как: актуальность; полнота раскрытия темы; четкость структуры изложения материала; использование научной терминологии и стиля; формулировка выводов
Отдельно необходимо отметить необходимость разнообразить формы и методы проведения контроля самостоятельной работы при дистанционном обучении, чтобы повысить мотивацию учащихся в достижении высоких результатов. В качестве письменных форм контроля самоподготовки, наиболее широко используются: деловое письмо, составление аннотации, реферирование, составление тезисов, написание доклада. К устным формам можно отнести выступление с докладом или презентацией, ситуативное задание, которое требует от студента принятия рационального практического решения, таким образом наиболее полно отражая глубину знаний студента и уровень владения ими. В настоящее время широко применяется компьютерное тестирование. Основным достоинством этого формата является возможность индивидуализации контроля и удобство при проведении и проверке. По мере совершенствования и внедрения в учебный процесс новых видов самостоятельной работы, формы контроля также необходимо совершенствовать [3, с.85].

Следует отметить, что факторы социальной и медийной среды усиливают свое влияние, поскольку человек начинает понимать, с какими социальными потребностями он сталкивается, насколько сложным и разнообразным должен быть освоен мир медиа, чтобы быть социально и профессионально мобильным. При этом факторы вузовской образовательной среды способствуют этому либо через учебные дисциплины, связанные со средствами массовой информации, либо через современные методы и технологии обучения, а также позицию преподавателей и их личный пример. Влияние внутриличностных факторов существенно. Это система личностных ценностей, мотивов и приоритетов, таких как наличие позитивного индивидуального настроя в освоении новых компетенций; личный опыт работы в информационной среде; так как успешность формирования личностной медиакомпетентности во многом зависит от целостности личности.

В настоящее время медиасреда становятся более доступной и открытой, Учебный процесс высшей школы дополняется новым содержанием, методами и технологиями, соответствующими практике, возрастает роль внутриличностных факторов в освоении неформальных видов образовательной деятельности. Готовность студентов к самообучению в реальной медиасреде обуславливается уровнем сформированности навыков самоподготовки. Это происходит в процессе учебно-профессиональной деятельности, которая протекает в рамках социо-культурной академической среды. Последующее развитие этого процесса может продолжаться и вне вуза, например, в процессе повышения квалификации, освоения новой профессии, а также любого интеллектуального совершенствования личности. 
Таким образом, формирование готовности и совершенствование навыков студентов к самообучению на этапе вузовского образования можно представить как систему взаимозависимых и дополняющих друг друга компонентов. Способы педагогического воздействия на процесс совершенствования этой готовности с учетом указанных факторов, включают расширение информационно-образовательной среды высшего учебного заведения, которая будет непосредственно влиять на факторы организации учебного процесса. С другой стороны, требуется повышение компетентности профессорско-преподавательского состава высшей школы, как в плане компьютерной грамотности, так и в области педагогического проектирования образовательного процесса на стыке формальной и неформальной форм обучения.

По окончании вуза готовность к самообучению может поддерживаться, причем значительную роль в развитии этой готовности играют как факторы социальной и медийной среды, так и внутриличностные факторы, поскольку только человек, имеющий постоянную потребность в саморазвитии и сформировавшуюся готовность к самообучению, способен добиться успеха в освоении нового и продолжить самосовершенствоваться в течении всей жизни.

\section{ЛИТЕРАТУРА}

1. Акманова, С.В. Медиаобразование как необходимое условие развития индивидуальных навыков самообучения в процессе непрерывного образования. Роль и место информационных технологий в современной науке.// Уфа: наука Омега, 2017, С. 54-55.

2. Горский В.А., Суворова Г.Ф., Смирнов Д.В. и др. Аль. Научные основы взаимодействия и преемственности формального, неформального и неформального образования. // Уфа: Изд-во ИРО РБ, 2012. - 308 с.

3. Обухова Л.Ю. Совершенствование контроля самостоятельной работы студентов.// Современная наука: актуальные проблемы теории и практики. Серия: Гуманитарные науки, 2018. № 2. С. 83-85.

4. Харланова Е.М. Развитие социальной активности студентов вуза в процессе интеграции формального и неформального образования.// Канд. Дис. Челябинск, 2015, 435с.

5. Челышева И.В. 2016 Стратегии развития российского медиаобразования: традиции и инновации.// Медиаобразование,. 2016, № 1, С. 71-77.

6. Чикилева Л.С. Роль тьютора в выборе инструментов педагогического управления для организации самостоятельной работы по иностранному языку // Интеграция образования. 2019. Т. 23. № 3 (96). С. 475-489.

7. Федоров А.В. Медиаобразование: история и теория.// М.: М00 «Информация для всех», 2015, 450 c.

8. Bal E. The purpose of students' social media use and determining their perspectives on education.// Procedia Computer Science, 2017, Vol. 120, pp. 177-181.

9. Beddie F., Halliday-Wynes S. Informal and Non-Formal Learning in Vocational Education and Training.// International Encyclopedia of Education (Third Edition), 2010, :pp. 240-246.

10. Weinstein C.E., Krause J.M, Stano N. International Encyclopedia of the Social \& Behavioral Sciences (Second Edition), 2015. pp. 712-719.

(c) Обухова Лариса Юрьевна (lora.yur@mail.ru). 